Marquette University

e-Publications@Marquette

$12-15-2014$

\title{
Mono- $N$-acyl-2,6-diaminopimelic Acid Derivatives: Analysis by Electromigration and Spectroscopic Methods and Examination of Enzyme Inhibitory Activity
}

Jan Hlaváček

Academy of Sciences of the Czech Republic

Miloslava Vítovcová

Academy of Sciences of the Czech Republic

Petra Sázelová

Academy of Sciences of the Czech Republic

Jan Pícha

Academy of Sciences of the Czech Republic

Václav Vaněk

Academy of Sciences of the Czech Republic

See next page for additional authors

Follow this and additional works at: https://epublications.marquette.edu/chem_fac

Part of the Chemistry Commons

\section{Recommended Citation}

Hlaváček, Jan; Vítovcová, Miloslava; Sázelová, Petra; Pícha, Jan; Vaněk, Václav; Buděšínský, Miloš; Jiráček, Jiř́i; Gillner, Danuta M.; Holz, Richard C.; Mikšík, Ivan; and Kašička, Václav,

"Mono- $\mathrm{N}$-acyl-2,6-diaminopimelic Acid Derivatives: Analysis by Electromigration and Spectroscopic Methods and Examination of Enzyme Inhibitory Activity" (2014). Chemistry Faculty Research and Publications. 355.

https://epublications.marquette.edu/chem_fac/355 


\section{Authors}

Jan Hlaváček, Miloslava Vítovcová, Petra Sázelová, Jan Pícha, Václav Vaněk, Miloš Buděšínský, Jiří Jiráček, Danuta M. Gillner, Richard C. Holz, Ivan Mikšík, and Václav Kašička

This article is available at e-Publications@Marquette: https://epublications.marquette.edu/chem_fac/355 
Marquette University

e-Publications@Marquette

\section{Chemistry Faculty Research and Publications/College of Arts and Sciences}

This paper is NOT THE PUBLISHED VERSION; but the author's final, peer-reviewed manuscript. The published version may be accessed by following the link in th citation below.

Analytical Biochemistry, Vol. 467 (December 15, 2014): 4-13. DOI. This article is (C) Elsevier and permission has been granted for this version to appear in e-Publications@Marquette. Elsevier does not grant permission for this article to be further copied/distributed or hosted elsewhere without the express permission from Elsevier.

\section{Mono-N-Acyl-2,6-Diaminopimelic Acid Derivatives: Analysis by Electromigration And Spectroscopic Methods and Examination of Enzyme Inhibitory Activity}

Jan Hlaváček

Institute of Organic Chemistry and Biochemistry, Academy of Sciences of the Czech Republic, 16610 Prague 6, Czech Republic

Miloslava Vítovcová

Institute of Organic Chemistry and Biochemistry, Academy of Sciences of the Czech Republic, 16610 Prague 6, Czech Republic

Petra Sázelová

Institute of Organic Chemistry and Biochemistry, Academy of Sciences of the Czech Republic, 16610 Prague 6, Czech Republic

Jan Pícha

Institute of Organic Chemistry and Biochemistry, Academy of Sciences of the Czech Republic, 16610 Prague 6, Czech Republic

Václav Vaněk 
Institute of Organic Chemistry and Biochemistry, Academy of Sciences of the Czech Republic, 16610 Prague 6, Czech Republic

Miloš Buděšínský

Institute of Organic Chemistry and Biochemistry, Academy of Sciences of the Czech Republic, 16610 Prague 6, Czech Republic

Jiří Jiráček

Institute of Organic Chemistry and Biochemistry, Academy of Sciences of the Czech Republic, 16610 Prague 6, Czech Republic

Danuta M. Gillner

Department of Chemistry and Biochemistry, Loyola University Chicago, Chicago, IL

Department of Chemistry, Silesian University of Technology, 44-100 Gliwice, Poland

Richard C. Holz

Department of Chemistry and Biochemistry, Loyola University Chicago, Chicago, IL

Ivan Mikšík

Institute of Physiology, Academy of Sciences of the Czech Republic, 14220 Prague 4, Czech Republic

Václav Kašičkaa

Institute of Organic Chemistry and Biochemistry, Academy of Sciences of the Czech Republic, 16610 Prague 6, Czech Republic

\section{Abstract}

Thirteen mono- $N$-acyl derivatives of 2,6-diaminopimelic acid (DAP) - new potential inhibitors of the dapEencoded $\mathrm{N}$-succinyl-I,I-diaminopimelic acid desuccinylase (DapE; EC 3.5.1.18)-were analyzed and characterized by infrared (IR) and nuclear magnetic resonance (NMR) spectroscopies and two capillary electromigration methods: capillary zone electrophoresis (CZE) and micellar electrokinetic chromatography (MEKC). Structural features of DAP derivatives were characterized by IR and NMR spectroscopies, whereas CZE and MEKC were applied to evaluate their purity and to investigate their electromigration properties. Effective electrophoretic mobilities of these compounds were determined by CZE in acidic and alkaline background electrolytes (BGEs) and by MEKC in acidic and alkaline BGEs containing a pseudostationary phase of anionic detergent sodium dodecyl sulfate (SDS) or cationic detergent cetyltrimethylammonium bromide (CTAB). The best separation of DAP derivatives, including diastereomers of some of them, was achieved by MEKC in an acidic BGE (500 mM acetic acid [pH 2.54] and $60 \mathrm{mM}$ SDS). All DAP derivatives were examined for their ability to inhibit catalytic activity of DapE from Haemophilus influenzae (HiDapE) and ArgE from Escherichia coli (EcArgE). None of these DAP derivatives worked as an effective inhibitor of HiDapE, but one derivative- $N$-fumaryl, Meester-DAP-was found to be a moderate inhibitor of ECArgE, thereby providing a promising lead structure for further studies on ArgE inhibitors.

\section{Keywords}

2,6-Diaminopimelic acid derivatives, Capillary zone electrophoresis, Micellar electrokinetic chromatography, Enzyme inhibition, IR spectroscopy, NMR spectroscopy

The World Health Organization reported that bacterial infections represent a significant and permanently growing medical problem around the world due to the increasing number of disease-causing microbes that have become resistant to currently available antibiotics [1], [2], [3]. In fact, several pathogenic bacteria, some of which were thought to have been eradicated, have made a significant resurgence due to bacterial resistance to antibiotics [4], [5]. For example, resistance to tetracyclinesincreased from 0\% in 1948 to $98 \%$ in 1998 [4], [5], and tuberculosis is currently one of the leading causes of death in adults by an infectious disease worldwide, which is significant given that death ratesdue to tuberculosis had declined to near 
imperceptible levels in industrial nations [6], [7]. According to the Centers for Disease Control and Prevention (USA), several bacterial strains currently exhibit multidrug resistance, with more than $60 \%$ of hospital-acquired infections in the United States alone caused by the so-called ESKAPE pathogens (Enterococcus faecium, Staphylococcus aureus, Klebsiella pneumoniae, Acinetobacter baumannii, $\underline{\text { Pseudomonas }}$ aeruginosa, and Enterobacter sp.). These findings have stimulated an intensive search for new potent antimicrobial agents that are active against drug-resistant bacterial strains [5], [8].

Inhibitors of cell wall biosynthesis - vancomycin and $\beta$-lactams, to name a couple-have proven to be very potent antibiotics, evidence that interfering with cell wall synthesis has deleterious effects on bacterial cell survival. Enzymes that are targeted by these antibiotics tend to be present in all bacteriaand are highly similar in structure and function. Unfortunately, only two new antibacterial drugs have emerged since 1962. Because every antibiotic has a finite lifetime given that resistance will ultimately occur, particularly if the same enzymes are repeatedly targeted, development of new classes of inhibitors that target previously untargeted cellular enzymes is essential to retain control of infectious disease [5], [8]. As such, antimicrobial peptides have been introduced as an innate defense system and shown to provide protection against a wide variety of microorganisms [9], [10], [11], [12]. Another approach targets microbial enzymes, especially those catalyzing metabolic processes exclusive to bacteria, as potential targets for potent and selective antibiotics [8].

Recently, we described a series of inhibitors for the bacterial enzyme $N^{\alpha}$-acetyl-I-ornithine deacetylase $(\mathrm{ArgE}), \underline{2}$ which catalyzes the conversion of $N^{\alpha}$-acetyl-I-ornithine to l-ornithine in the fifth step of the biosynthetic pathway for arginine, a necessary step for bacterial growth [13]. Based on bacterial geneticinformation, the meso-diaminopimelate (mDAP)/lysine biosynthetic pathway (Fig. 1) offers several potential antibacterial targets that have yet to be explored [14], [15], [16], [17]. One of the products of this pathway, lysine (10), is required in protein synthesis and is also used in the peptidoglycan layer of gram-positive bacteria cell walls. A second product, meso-diaminopimelic acid (mDAP) (9), is an essential component of the peptidoglycan cell wall in gram-negative bacteria, providing a link between polysaccharide strands. It has been shown that deletion of the gene encoding for one of the enzymes in the mDAP/lysine biosynthetic pathway, the DapE-encoded $\mathrm{N}$ succinyl-I,I-diaminopimelic acid desuccinylase (DapE; EC 3.5.1.18) [18], is lethal to Helicobacter pylori and Mycobacterium smegmatis [19], [20]. Even in the presence of lysine-supplemented media, $H$. pylori was unable to grow. Therefore, DapE is essential for cell growth and proliferation and is a part of a biosynthetic pathway that is the only source of lysine in bacteria. Because there are no similar biosynthetic pathways in mammals, inhibitors that target one or more of the enzymes in the mDAP/lysine biosynthetic pathway are hypothesized to exhibit selective toxicity only against bacteria, providing a previously nondescribed class of antimicrobial agents [14], [21].

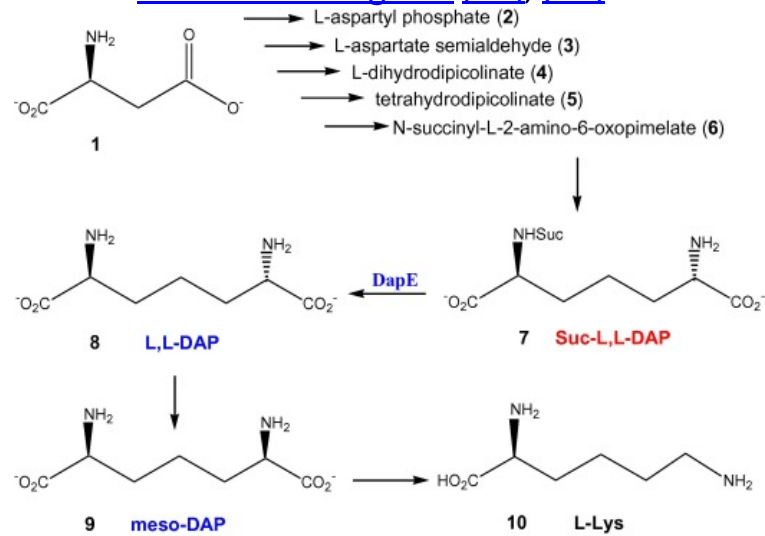

Fig.1. Biosynthetic reactions leading from aspartate to lysine: I-aspartate (1); $N$-succinyl-I,I-diaminopimelate (7); I,I-diaminopimelate (8); d,I-diaminopimelate (9); I-lysine (10).

With the aim of developing new antimicrobial agents that target DapE enzymes, a methodology for the quick and efficient preparation of mono- $N$-acylated 2,6-diaminopimelic acid (DAP) derivatives was recently 
reported [22]. These compounds were designed as competitive inhibitors of the mono- $N$-succinylDAP hydrolysis reaction catalyzed by DapE, in which the structure of the N-linked succinatemoiety was altered to inhibit the enzyme's ability to cleave the adjacent amide bond. The syntheses of a series of 13 DAP derivatives (Table 1) bearing different $\mathrm{N}$-linked acyl side chains comprising (i) a hydrophobic aliphatic or aromatic moiety (A1-A6), (ii) an aliphatic moiety terminated by a carboxyl group (C1-C4), (iii) an aliphatic moiety terminated by an ester group (E1-E3), and their purificationand characterization by high-performance liquid chromatography (HPLC), elemental analysis, and electrospray ionization-mass spectrometry (ESI-MS) were described previously [22].

Table 1. Name, indication, structural formula, and relative molecular mass $\left(M_{r}\right)$ of 2,6-diaminopimelic acid and its mono- $N$-acyl derivatives.

\begin{tabular}{|c|c|c|}
\hline Compound name and indication & Structural formula & $M_{\mathrm{r}}$ \\
\hline 2,6-Diaminopimelic acid & & 190.2 \\
\hline \multicolumn{3}{|l|}{ DAP } \\
\hline$N$-Acetyl-DAP & & 232.1 \\
\hline \multicolumn{3}{|l|}{ A1 } \\
\hline$N$-Isobutyryl-DAP & & 260.3 \\
\hline \multicolumn{3}{|l|}{ A2 } \\
\hline$N$-Butyryl-DAP & & 260.3 \\
\hline \multicolumn{3}{|l|}{ A3 } \\
\hline N-Pivalyl DAP & & 274.3 \\
\hline \multicolumn{3}{|l|}{ A4 } \\
\hline$N$-Valeryl-DAP & & 274.3 \\
\hline
\end{tabular}




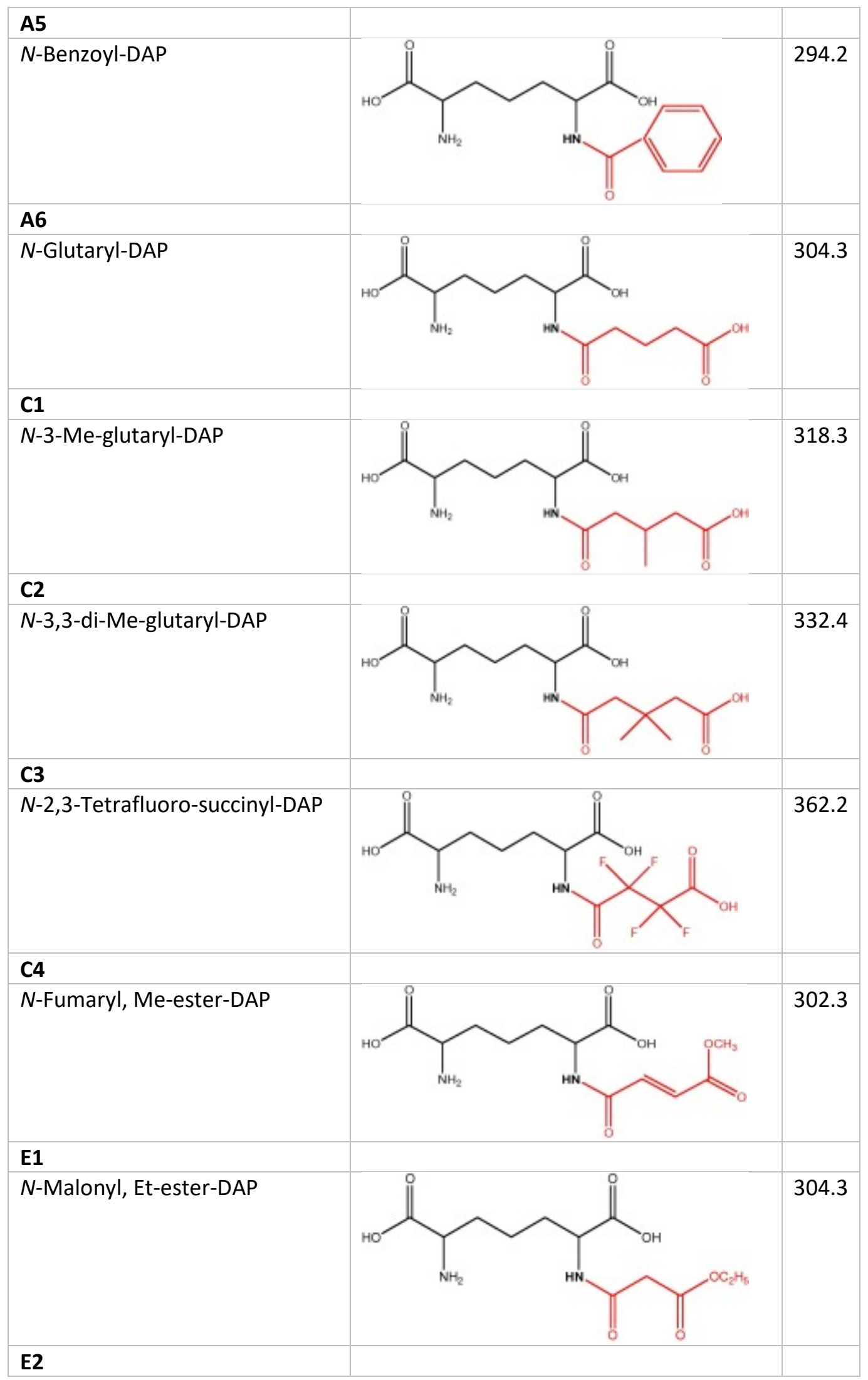




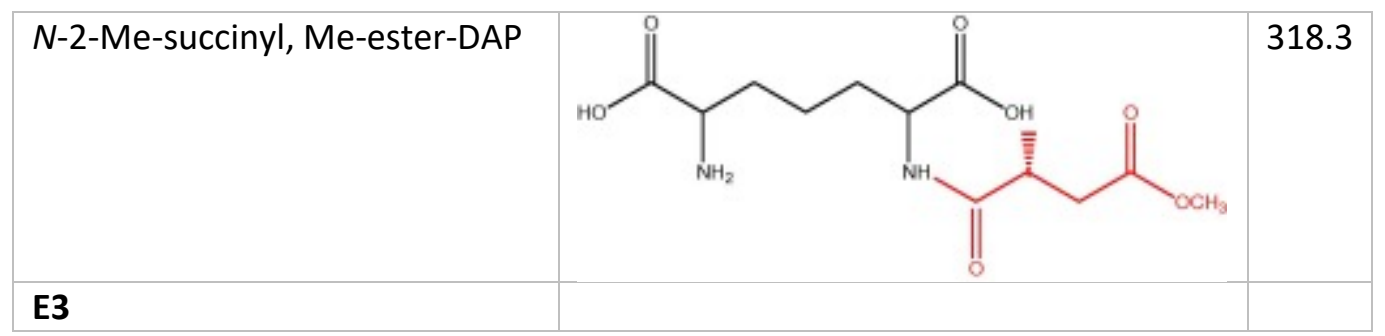

We report here the analytical characterization of these DAP derivatives in order to confirm their structural properties using infrared (IR) and ${ }^{1} \mathrm{H}$ and ${ }^{13} \mathrm{C}$ nuclear magnetic resonance (NMR) spectroscopies. We also performed qualitative and quantitative analysis of each of these compounds by two capillary electromigration methods: capillary zone electrophoresis (CZE) and micellar electrokinetic chromatography (MEKC). These two techniques are excellent tools for separation of both ionogenic and electroneutral compounds [23], [24], [25] and are frequently used for analysis and characterization of amino acids and their derivatives [26], [27], [28]. In addition, these DAP derivatives were characterized by their effective electrophoretic mobilities determined by CZE in acidic and alkaline classical or isoelectric background electrolytes (BGEs) or by MEKC in acidic and alkaline BGEs containing a micellar pseudostationary phase constituted by the anionic detergent sodium dodecyl sulfate (SDS) or the cationic detergent cetyltrimethylammonium bromide (CTAB). Finally, all of these DAP derivatives were tested for their inhibition activity toward both DapE and ArgE.

\section{Materials and methods}

\section{Chemicals}

All chemicals used were of analytical reagent grade. Tris(hydroxymethyl)aminomethane (Tris) was purchased from Serva (Heidelberg, Germany). Phosphoric acid $\left(\mathrm{H}_{3} \mathrm{PO}_{4}\right)$, acetic acid $(\mathrm{AcOH})$, and sodium hydroxide $(\mathrm{NaOH})$ were obtained from Lachema (Brno, Czech Republic). Iminodiacetic acid(IDA) was obtained from Bachem (Bubendorf, Switzerland). SDS and CTAB were supplied by Fluka (Buchs, Switzerland). Acetonitrile (ACN) was obtained from Sigma-Aldrich (Prague, Czech Republic) and methanol (MeOH) from Penta (Chrudim, Czech Republic).

\section{IR and NMR spectroscopies}

Fourier transform (FT)-IR spectra $\left(\mathrm{KBr}, v_{\max } \mathrm{cm}^{-1}\right)$ were recorded on a Nicolet $6700 \mathrm{FT}$-IR instrument (Madison, WI, USA). ${ }^{1} \mathrm{H}$ and ${ }^{13} \mathrm{C}$ NMR spectra were obtained on a Bruker AVANCE-600 NMR spectrometer (Bruker BioSpin, Rheinstetten, Germany) using a 5-mm CPTCl cryoprobe $\left({ }^{1} \mathrm{H}\right.$ at $600.13 \mathrm{MHz},{ }^{13} \mathrm{C}$ at $\left.150.9 \mathrm{MHz}\right)$ in dimethyl sulfoxide (DMSO)- $\mathrm{d}_{6}$ at $300 \mathrm{~K}$. A series of proton 1D (one-dimensional), 2D-COSY (two-dimensional correlation spectroscopy), 2D-TOCSY (total correlation spectroscopy) (spin-lock time $90 \mathrm{~ms}$ ), and 2D-ROESY (rotating frame NOE [nuclear Overhauser effect] spectroscopy) (mixing time $300 \mathrm{~ms}$ ) spectra were recorded at $27^{\circ} \mathrm{C}$ for complete structural assignment of the observed proton signals. The structural assignment of the ${ }^{13} \mathrm{C}$ signals was achieved by combining 1D-APT (attached proton test), 2D-H,C-HSQC (heteronuclear single quantum coherence), and $2 \mathrm{D}-\mathrm{H}, \mathrm{C}-\mathrm{HMBC}$ (heteronuclear multiple bond coherence) spectra.

\section{Capillary electromigration methods}

CZE and MEKC were performed on a homemade manually operated apparatus for high-performance capillary electrophoresis [29] equipped with an ultraviolet (UV) absorption photometric detector operating at $206 \mathrm{~nm}$. Internally untreated fused silica capillary with outer polyimide coating (Polymicro Technologies, Phoenix, AZ, USA) with inner diameter of $50 \mu \mathrm{m}$, outer diameter of $375 \mu \mathrm{m}$, total length of $400 \mathrm{~mm}$, and effective length (from injection to detector) of $290 \mathrm{~mm}$ was used for all separations. Data acquisition and evaluation was carried out by Chromatography and ElectrophoresisStation Clarity (DataApex, Prague, Czech Republic). The analyzed DAP derivatives were dissolved in the BGE or water in the concentration range 0.5 to $1.1 \mathrm{mg} / \mathrm{ml}$ and were analyzed as cations in acidic BGEs or as anions in alkaline BGEs. The BGEs were passed through a $0.45-\mu \mathrm{m}$ Millipore filter (Bedford, MA, USA). The nanoliter sample volumes were introduced into the capillary 
hydrodynamically by pneumatically induced pressure $(600-1000 \mathrm{~Pa}$ ) for a period of 3 to $20 \mathrm{~s}$. The applied separation voltagewas $+12 \mathrm{kV}$ or $-12 \mathrm{kV}$ (anode or cathode at the injection capillary end), whereas the electric current was in the range 7.1 to $45.0 \mu \mathrm{A}$ at an ambient temperature of 22 to $26^{\circ} \mathrm{C}$.

\section{Determination of $\mathrm{IC}_{50}$}

The DapE from Haemophilus influenzae (HiDapE) was purified as described previously [18]. IC 50 values were determined using $3 \mathrm{mM} \mathrm{N}$-succinyl-2,6-diaminopimelic acid (mixture of $\mathrm{d}, \mathrm{d}-\mathrm{l}$,l isoforms, 1:1) as the substrate. All kinetic experiments were performed in $50 \mathrm{mM}$ Chelex-100-treated sodium phosphatebuffer at pH 7.5 and $25^{\circ} \mathrm{C}$. Catalytic activities were determined by monitoring the initial rates of amidebond cleavage at $225 \mathrm{~nm}$ $\left(\varepsilon=698 \mathrm{M}^{-1} \mathrm{~cm}^{-1}\right.$ ) in $50 \mathrm{mM}$ phosphate buffer ( $\mathrm{pH} \mathrm{7.0)}$ on a Shimadzu UV-2600 UV-Vis (ultraviolet-visible) spectrometer at $25^{\circ} \mathrm{C}$ in the presence of two equivalents of $\mathrm{Zn}(\mathrm{II})$. Measurements were performed in triplicate at a minimum of five inhibitor concentrations. Enzyme activities were expressed as units per milligram, where 1 unit is defined as the amount of enzyme that cleaves $1 \mu \mathrm{mol}$ of dd,II-N-succinyl-2,6-diaminopimelic acid at $25^{\circ} \mathrm{C}$ in $1 \mathrm{~min}$. These data provide a dose-response curve that allows for the concentration required for $50 \%$ inhibition $\left(\mathrm{IC}_{50}\right)$ of DapE to be extracted.

The ArgE from Escherichia coli (EcArgE) was purified as described previously [30]. IC 50 values were determined spectrophotometrically using $2 \mathrm{mM} \mathrm{N}{ }^{\alpha}$-acetyl-I-ornithine (L-NAO) as the substrate. The rate of LNAO deacetylation was monitored as a decrease in absorbance at $214 \mathrm{~nm}$ using a Shimadzu UV-2600 UV-Vis spectrophotometer at $25^{\circ} \mathrm{C}$. All kinetic experiments were performed in $50 \mathrm{mM}$ Chelex-100-treated sodium phosphate buffer at $\mathrm{pH} 7.5$ and $25^{\circ} \mathrm{C}$. Initial rates of L-NAO deacetylationwere determined in triplicate at a minimum of five inhibitor concentrations, providing a dose-response curve from which the concentration required for $50 \%$ inhibition $\left(\mathrm{IC}_{50}\right)$ of ArgE could be extracted. Catalytic activities were determined with an error of $\pm 10 \%$.

\section{Results and discussion}

\section{IR and NMR spectroscopies}

The structural features of the DAP derivatives were characterized by IR and NMR spectroscopies. IR $\left(\mathrm{KBr}, v_{\max } \mathrm{cm}^{-1}\right)$ spectra of each of the DAP derivatives reveal characteristic bands corresponding to the functional groups present in these compounds (see Table SI-1 in the online supplementary material) - that is, broad bands in the range $v\left(3427-3050 \mathrm{~cm}^{-1}\right)$ due to amino groups and/or carboxylic $\mathrm{OH}$ groups, relatively sharp bands in the $v\left(1735-1726 \mathrm{~cm}^{-1}\right)$ range due to carboxylic $\mathrm{C}=0$ groups, and bands in the $v\left(1670-1630 \mathrm{~cm}^{-1}\right)$ and $v\left(1550-1522 \mathrm{~cm}^{-1}\right)$ ranges due to amide I and amide II groups, respectively. The IR spectra also show distinct $\mathrm{C}=\mathrm{O}$ and/or $\mathrm{C} \_\mathrm{F}$ bands at $v \sim 1200 \mathrm{~cm}^{-1}$ due to trifluoroacetatecounterions, which originate from the HPLC purification of DAP derivatives where $0.05 \%(\mathrm{v} / \mathrm{v})$ trifluoroacetic acid was used as an acid modifier of the mobile phase.

The ${ }^{1} \mathrm{H}$ and ${ }^{13} \mathrm{C}$ chemical shift data for each DAP derivative were assigned according to the following general formula:

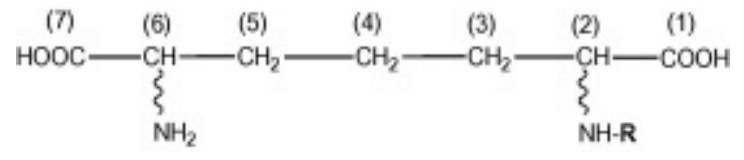

where $\mathbf{R}$ indicates the various acyl substituents (see Tables SI-2 and SI-3 in supplementary material). Signals due to minor isomers (if resolved from a major isomer) are in italics. The series of DAP derivatives examined were prepared from an enantiomeric/diastereomeric mixture of $R S, R S-2,6$-diaminopimelic acid, and the mixtures of two diastereoisomeric forms were also detected. Due to the additional chiral center on the acyl substituent $\mathbf{R}$ in compounds $\mathbf{C 2}$ and $\mathbf{E 3}$, ratios of four isomerswithout any ascribed priority were estimated. 


\section{Capillary electromigration methods}

\section{Selection of experimental conditions}

The DAP derivatives examined (Table 1) are typical amphoteric compounds containing both acidic (carboxylic) and basic (amino) groups with different acyl substituents $\mathbf{R}$ on one of the two amino groups. Hence, the experimental conditions for CZE and MEKC analyses and separations of DAP derivatives were selected based on the general rules for suitable capillary electrophoresis separation conditions for amino acids and oligopeptides [31], [32], [33], [34], [35] while also taking into account the specific properties of the DAP derivatives. The selection of BGEs includes the type and concentration of buffer components and $\mathrm{pH}$, and it also takes into account the solubility and chemical stability of each compound. Effective mobility of weak electrolytes and ampholytes strongly depends on $\mathrm{pH}$; therefore, $\mathrm{pH}$ is one of the most important parameters influencing separation efficiency and selectivity of the BGEs.

For CZE analysis and separation of amphoteric DAP derivatives, either acidic or alkaline BGEs are suitable. Therefore, the following BGEs were used: (i) acidic BGEs ( $\mathrm{pH}$ 2.18-2.54) in which the amino groups are fully protonated and the carboxylic groups are only partially dissociated, resulting in cationic migration of the DAP derivatives; and (ii) basic BGEs ( $\mathrm{pH} 8.20-8.64)$ in which the amino groups are partially protonated and the carboxylic groups are fully dissociated, resulting in anionic migration of the DAP derivatives. BGE compositions were also selected with respect to their buffering capacity in order to maintain proper $\mathrm{pH}$ in the zone of migrating analytes (i.e., $\mathrm{pH}$ of the $\mathrm{BGE}$ was close to the $\mathrm{p} K_{\mathrm{a}}$ value of the buffering constituent of the BGE). With the addition of anionic (SDS) or cationic (CTAB) detergents, the same BGEs were also employed for the separation of DAP derivatives by MEKC. The complete composition and $\mathrm{pH}$ of the BGEs used, as well as the separation voltages and electric currents employed in the CZE and MEKC analyses and separations of DAP derivatives, are presented in Table 2.

Table 2. Background electrolytes, separation voltage $\left(U_{\text {sep }}\right)$, and electric current $(I)$ used in CZE and MEKC methods.

\begin{tabular}{|c|c|c|c|c|c|}
\hline BGE number & BGE composition & pH & Method & $U_{\text {sep }}(\mathrm{kV})$ & $I(\mu \mathrm{A})$ \\
\hline BGE I & $500 \mathrm{mM} \mathrm{AcOH}$ & 2.54 & CZE & 12.0 & 7.1 \\
\hline BGE II & $100 \mathrm{mM}$ Tris, $50 \mathrm{mM} \mathrm{AcOH}$ & 8.20 & CZE & 12.0 & 23.3 \\
\hline BGE III & $20 \mathrm{mM}$ Tris, $5 \mathrm{mM} \mathrm{H}_{3} \mathrm{PO}_{4}, 50 \mathrm{mM}$ SDS & 8.64 & MEKC & 12.0 & 18.6 \\
\hline BGE IV & $200 \mathrm{mM}$ iminodiacetic acid & 2.28 & CZE & 12.0 & 35.0 \\
\hline BGE V & $50 \mathrm{mM}$ Tris, $100 \mathrm{mM} \mathrm{H}_{3} \mathrm{PO}_{4}$ & 2.18 & CZE & 12.0 & 45.0 \\
\hline BGE VI & $500 \mathrm{mM} \mathrm{AcOH}, 60 \mathrm{mM}$ SDS & 2.54 & MEKC & -12.0 & 24.0 \\
\hline BGE VII & $100 \mathrm{mM}$ Tris, $50 \mathrm{mM} \mathrm{AcOH}, 5 \mathrm{mM}$ CTAB & 8.20 & MEKC & -12.0 & 23.0 \\
\hline BGE VIII & $100 \mathrm{mM}$ Tris, $50 \mathrm{mM} \mathrm{AcOH}, 10 \mathrm{mM}$ CTAB & 8.20 & MEKC & -12.0 & 23.5 \\
\hline
\end{tabular}

\section{Determination of purity of DAP derivatives}

DAP derivatives were synthesized for the first time; their standard preparations were not available, and for that reason their purity degree could be quantified only relatively by the relative corrected peak area, $P_{\mathrm{CA}}[36]$, defined by the following relation:

$$
\text { (1) } P_{\mathrm{CA}(i)}(\%)=\frac{A_{\mathrm{c},(i)}}{\sum_{i=1}^{n} A_{\mathrm{c},(i)}} \cdot 100
$$

where $A_{c,(i)}$ is the corrected peak area of the $i$-th component of the given preparation and $n$ is the number of components of this preparation. Corrected peak area is the peak area normalized (divided) by the migration time of this peak. This way, defined purity degree is only an approximate measure of analyte purity given that molar absorption coefficients of the individual components may differ. Nevertheless, with respect to the 
expected structural similarity of the admixtures and main synthetic product, it is reasonable to assume similar values of their molar absorption coefficients and, thus, also a relatively good estimation of the purity degree of the main product.

Analyses and purity degree determinations were performed by CZE in the acidic BGE I and alkaline BGE II and by MEKC in the alkaline BGE III. The $P_{C A}$ for each DAP derivative is summarized in Table 3 . For all analytes, high degrees of purity were observed with $P_{C A}$ values in the range 95.0 to $\sim 100 \%$. For comparison purposes, CE analyses for the DAP derivatives E1 and C3 in the electrolyte systems BGE I, BGE II, and BGE III are discussed further. The derivative E1 was found to be highly pure $\left(P_{\mathrm{CA}} \sim 100 \%\right)$ in all three BGEs (Figs. 2A-C and Table 3 ). For the DAP derivative $\mathbf{C 3}$, one nonidentified admixture (peak $\mathrm{x}$ ) with lower electrophoretic mobility than that of the analyte C3 was found in BGE I and BGE II, and its purity was found to be $94.8 \%$ in BGE I and $94.1 \%$ in BGE II (Figs. 2D and 2E and Table 3). However, MEKC performed in BGE III revealed three nonidentified minor admixtures $-x 1, \times 2$, and $\times 3-$ and its purity was found to be $90.8 \%$ (Fig. $2 \mathrm{~F}$ and Table 3 ). These and other examples show that significant differences in purity were detected, depending on the method (CZE or MEKC) and BGE used. CZE analyses on analyte C1 in BGEs I and II suggest high purity ( $P_{\mathrm{CA}} \sim 100 \%$ ), but MEKC in BGE III revealed two minor admixtures $x 1$ and $x 2$ and purity of $94.5 \%$ (see Figs. SI-1A-C in supplementary material). The analyte $\mathrm{C} 4$ exhibits high purity $\left(P_{\mathrm{CA}} \sim 100 \%\right)$ when analyzed as a cationby CZE in acidic BGE I, but CZE in alkaline BGE II and MEKC in alkaline BGE III with SDS pseudostationary phase revealed one or two minor admixtures indicating lower purity-97.1 and 95.0\%, respectively (Figs. SI-1D-F) Thus, MEKC in BGE III with SDS seems to be more efficient for analysis of DAP derivatives than CZE because it was able to separate admixtures, which remained unrevealed by CZE analyses in BGEs I and II.

Table 3. Purity degree $\left(P_{C A}\right)$ of DAP and its mono- $N$-acyl-DAP derivatives estimated by CZE in BGE I and BGE II and by MEKC in BGE III.

\begin{tabular}{|l|l|l|l|}
\hline PA (\%) & & & \\
\hline Compound & BGE I & BGE II & BGE III \\
\hline DAP & pH 2.54 & pH 8.20 & pH 8.64 \\
\hline A1 & 9100 & $\sim 100$ & $\sim 100$ \\
\hline A2 & 94.5 & 93.6 & 93.7 \\
\hline A3 & 95.8 & 95.4 & 96.1 \\
\hline A4 & 94.3 & 97.1 & 97.0 \\
\hline A5 & 95.6 & 95.0 & 95.8 \\
\hline A6 & 95.2 & 95.4 & 95.6 \\
\hline C1 & $\sim 100$ & $\sim 100$ & 96.2 \\
\hline C2 & 96.9 & 98.4 & 93.5 \\
\hline C3 & 94.8 & 94.1 & 90.8 \\
\hline C4 & $\sim 100$ & 97.1 & 95.0 \\
\hline E1 & $\sim 100$ & $\sim 100$ & $\sim 100$ \\
\hline E2 & 94.3 & 91.4 & 95.1 \\
\hline E3 & 94.4 & 93.4 & 95.9 \\
\hline
\end{tabular}

Note. For names and structures of the compounds, see Table 1. For composition of the BGEs, see Table 2. 

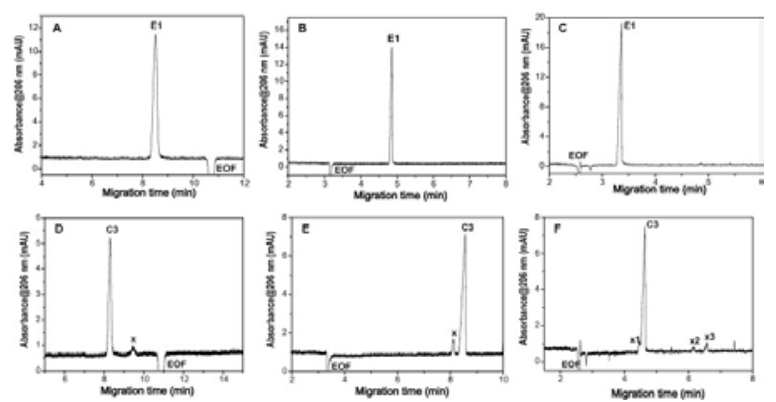

Fig.2. Analyses of DAP derivatives E1 and C3 by CZE in BGE I and BGE II and by MEKC in BGE III: (A) E1 by CZE in BGE I; (B) E1 by CZE in BGE II; (C) E1 by MEKC in BGE III; (D) C3 by CZE in BGE I; (E) C3 by CZE in BGE II; (F) C3 by MEKC in BGE III. Sample injection: hydrodynamic, 10 mbar $\times 5 \mathrm{~s}, \mathrm{x}, \mathrm{x1}, \mathrm{x2}, \mathrm{x3}$, nonidentified admixtures. For DAP derivative names and structures, see Table 1. The BGE composition and other experimental conditions are given in Table 2 and in "Materials and Methods".

\section{Characterization of DAP derivatives}

DAP derivatives were also characterized by their effective electrophoretic mobilities in eight BGEs. The

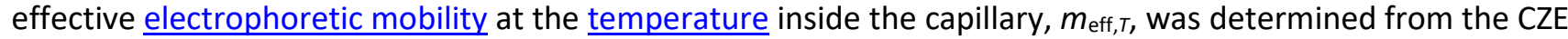
and MEKC experimental data using the Eq. (2):

(2) $m_{\mathrm{eff}, T}=\left(\frac{1}{t_{\mathrm{mig}}}-\frac{1}{t_{\mathrm{eof}}}\right) \cdot \frac{L_{\mathrm{eff}} \cdot L_{\mathrm{tot}}}{U_{\mathrm{sep}}}$

where $t_{\text {mig }}$ is the migration time of the given analyte $(\mathrm{s}), t_{\text {eof }}$ is the migration time of the electroosmotic flow marker $(\mathrm{s}), L_{\text {eff }}$ and $L_{\text {tot }}$ are the effective and total capillary lengths $(\mathrm{m})$, respectively, and $U_{\text {sep }}$ is the applied separation voltage (V). CZE and MEKC experiments were performed at different ambient temperatures (22$26^{\circ} \mathrm{C}$ ) and variable input power (Joule heat). To compare the observed mobilities, the actual mobility at temperature $T$ inside the capillary was recalculated to a reference mobility at $25^{\circ} \mathrm{C}, m_{\text {eff,25, }}$ using Eq. (3):

(3) $m_{\mathrm{eff}, 25}=m_{\mathrm{eff}, T}[1-0.020(T-25)]$

The actual temperature inside the capillary for each BGE was obtained based on the experimentally measured dependence of temperature increase inside the capillary on the input power (Joule heat) per unit capillary length as described previously [37].

The values for effective electrophoretic mobilities of DAP derivatives in eight BGEs at $25^{\circ} \mathrm{C}$ are presented in Table 4. These data exhibit a strong dependence of mobilities of DAP derivatives on $\mathrm{pH}$ and reflect the presence of the particular ionogenic groups and the ratio of effective charge versus size $\left(M_{r}\right)$ of these compounds. Cationic effective electrophoretic mobilities determined by CZE in the acidic BGE I ( $0.5 \mathrm{M} \mathrm{AcOH}, \mathrm{pH}$ 2.54) were relatively low at approximately 5.0 MU ( $\mathrm{MU}=$ mobility unit $\left.=1 \times 10^{-9} \mathrm{~m}^{2} \mathrm{~V}^{-1} \mathrm{~s}^{-1}\right)$ due to compensation of the positive charge of the amino group of DAP derivatives by the partially negative charges of their two or three carboxyl groups. Interestingly, in the C4 DAP derivative, four fluorine atoms in the side chain significantly increased the acidity of the corresponding carboxyl group, resulting in a prevailing anionic form of this compound with negative effective mobility even in the acidic BGE I (pH 2.54). In CZE analyses in alkaline BGE II (100 mM Tris and $50 \mathrm{mM}$ acetic acid, $\mathrm{pH}$ 8.20), all analyzed DAP derivatives migrated as anions. The derivatives $\mathbf{A} \mathbf{1}$ to $\mathbf{A} \mathbf{6}$ and $\mathbf{E} \mathbf{1}$ to $\mathbf{E} \mathbf{3}$ exhibited similar moderate negative effective mobilities in the range -13.6 to 15.7 MU due to similar ratios of their effective charges and molecular masses. The derivatives $\mathbf{C} \mathbf{1}$ to $\mathbf{C} 4$ containing the $\mathrm{N}$-acyl substituent with additional free carboxyl groups possessed an increased negative charge and exhibited enhanced anionic mobilities in the range -23.3 to $-25.2 \mathrm{MU}$ for compounds $\mathbf{C} 1$ to $\mathbf{C} 3$ and up to $-30.4 \mathrm{MU}$ for the most strongly negatively charged derivative $\mathbf{C 4}$. 
Table 4. Effective electrophoretic mobilities at $25^{\circ} \mathrm{C}$ of DAP derivatives determined by CZE in BGEs I, II, IV, and V and by MEKC in BGEs III, VI, VII, and VIII.

\begin{tabular}{|c|c|c|c|c|c|c|c|c|}
\hline & $\left.m_{1}\right)$ & & & & & & & \\
\hline \multirow[t]{2}{*}{$\begin{array}{l}\text { DAP } \\
\text { derivative }\end{array}$} & BGE I & BGE II & BGE III & BGE IV & BGE V & BGE VI & BGE VII & $\begin{array}{l}\text { BGE } \\
\text { VIII }\end{array}$ \\
\hline & pH 2.54 & $\begin{array}{l}\mathrm{pH} \\
8.20\end{array}$ & $\begin{array}{l}\mathrm{pH} \\
8.64\end{array}$ & $\begin{array}{l}\mathrm{pH} \\
2.28\end{array}$ & $\begin{array}{l}\mathrm{pH} \\
2.18\end{array}$ & $\begin{array}{l}\mathrm{pH} \\
2.54\end{array}$ & $\begin{array}{l}\mathrm{pH} \\
8.20\end{array}$ & pH 8.20 \\
\hline \multirow[t]{2}{*}{$\mathrm{A} 1$} & 4.7 & -15.7 & -14.2 & 7.3 & $8.5^{\mathrm{a}}$ & $-9.2^{\mathrm{a}}$ & -14.2 & -13.0 \\
\hline & & & & & $8.3^{a}$ & $-9.1^{\mathrm{a}}$ & & \\
\hline \multirow[t]{2}{*}{$\mathrm{A} 2$} & 5.0 & -14.8 & -13.6 & 7.0 & $7.8^{\mathrm{a}}$ & $-16.6^{\underline{a}}$ & -11.9 & -10.8 \\
\hline & & & & & $7.7^{a}$ & $-16.5^{\mathrm{a}}$ & & \\
\hline \multirow[t]{2}{*}{ A3 } & 4.8 & -14.6 & -13.2 & 7.0 & 7.9 & $-17.8^{\mathrm{a}}$ & -11.8 & -10.0 \\
\hline & & & & & & $-17.6^{\mathrm{a}}$ & & \\
\hline \multirow[t]{2}{*}{ A4 } & 5.0 & -14.5 & -12.7 & 6.9 & 7.9 & -21.7 & -9.3 & -6.8 \\
\hline & & & & & 7.8 & & & \\
\hline \multirow[t]{2}{*}{ A5 } & 4.7 & -13.9 & -12.2 & 6.7 & 7.6 & $-23.1^{\mathrm{a}}$ & -8.7 & -6.1 \\
\hline & & & & & & $-23.0^{\mathrm{a}}$ & & \\
\hline \multirow[t]{2}{*}{ A6 } & 4.4 & -13.9 & -11.4 & 6.6 & 8.1 & $-25.7^{a}$ & $-1.2^{\mathrm{a}}$ & 4.9 \\
\hline & & & & & & $-25.6^{\mathrm{a}}$ & $-0.7^{a}$ & \\
\hline $\mathrm{C} 1$ & 4.1 & -25.2 & -23.2 & 6.3 & 7.0 & -10.6 & -15.3 & -10.5 \\
\hline \multirow[t]{2}{*}{$\mathrm{C} 2$} & 4.3 & -24.0 & -23.6 & 6.3 & 7.4 & $-14.0^{\mathrm{a}}$ & -12.3 & -7.4 \\
\hline & & & & & & $-15.9^{a}$ & & \\
\hline C3 & 4.3 & -23.3 & -22.9 & 6.2 & 7.4 & -20.6 & -8.3 & $\sim 0$ \\
\hline C4 & -2.4 & -30.4 & -29.6 & $\sim 0$ & -10.3 & -12.9 & 28.0 & 28,6 \\
\hline \multirow[t]{2}{*}{ E1 } & 3.5 & -14.0 & -11.1 & 6.0 & 7.3 & $-16.0^{\mathrm{a}}$ & -9.4 & -7.5 \\
\hline & & & & & & $-15.8^{a}$ & & \\
\hline \multirow[t]{2}{*}{ E2 } & 4.1 & -14.3 & -12.1 & 6.7 & $7.7^{\mathrm{a}}$ & -19.2 & -11.9 & -9.4 \\
\hline & & & & & $7.6^{\mathrm{a}}$ & & & \\
\hline \multirow[t]{2}{*}{ E3 } & 4.9 & -13.6 & -11.7 & 6.9 & 7.9 & $-19.2^{\mathrm{a}}$ & -11.5 & -9.1 \\
\hline & & & & & & $-18.9^{a}$ & & \\
\hline
\end{tabular}

Note. For DAP derivative names and structures, see Table 1. The BGE composition and other experimental conditions are given in Table 2 and in Materials and Methods.

${ }^{a}$ Effective mobility of resolved diastereomer of DAP derivative.

Similar electromigration behavior was observed in the MEKC analyses of DAP derivatives in BGE III (20 mM Tris, $5 \mathrm{mM} \mathrm{H}_{3} \mathrm{PO}_{4}$, and $50 \mathrm{mM} \mathrm{SDS}, \mathrm{pH}$ 8.64), where derivatives $\mathbf{A} 1$ to $\mathbf{A 6}$ and $\mathbf{E 1}$ to E3exhibited anionic mobilities in the range -11.1 to $-14.2 \mathrm{MU}$ and the mobilities of the compounds $\mathbf{C} 1$ to $\mathbf{C} 4$ achieved values of -22.9 to 29.6 MU. The small observed difference between mobilities in the micelle-free BGE II and those in the micellecontaining BGE III suggests that the DAP derivatives do not strongly interact with the SDS micellar pseudophase of BGE III.

In the CZE analyses of DAP derivatives in the isoelectric BGE IV (200 mM IDA, pH 2.28) and in the classical BGE V (100 $\mathrm{mM} \mathrm{H}_{3} \mathrm{PO}_{4}$ and $50 \mathrm{mM}$ Tris, $\mathrm{pH}$ 2.18), similar structure-mobility relationships of these compounds were observed as in the BGE I. Slightly higher cationic mobilities were observed in BGEs IV and V ( 6.0-8.0 MU) than in BGE I (4.0-5.0 MU), which is due to the increased positive charge of the DAP derivatives at lower pH in BGEs $\mathrm{IV}$ and $\mathrm{V}(\mathrm{pH} 2.28$ and 2.18) than in BGE I (pH 2.54). The exception to this behavior is compound $\mathrm{C4}$, which exhibited negative mobility even under strongly acidic conditions in BGEs IV and V. 
An interaction between the positively charged DAP derivatives and the negatively charged SDS micellesin acidic BGE VI (0.5 M AcOH, pH 2.54) resulted in a negatively charged analyte-micelle complex with variable negative mobilities in the range -9.1 to $-25.7 \mathrm{MU}$ for compounds $\mathbf{A 1}$ to $\mathbf{A 6}$ and $\mathbf{E 1}$ to $\mathbf{E} 3$ and in the range -10.6 to 20.6 MU for compounds $\mathbf{C} \mathbf{1}$ to $\mathbf{C 4}$. In this case, the differences in mobilities did not result from differences in the charge/size ratio but rather resulted from differences in the hydrophobicities of the analytes and from the binding strength of their complexes with SDS micelles.

Negative effective charge and negative mobility were observed for nearly all DAP derivatives (with the exception of A6 and C4) in alkaline media such as BGE VII (100 mM Tris, $50 \mathrm{mM} \mathrm{AcOH}$, and $5 \mathrm{mM} \mathrm{CTAB}, \mathrm{pH} 8.2)$ and BGE VIII (100 mM Tris, $50 \mathrm{mM} \mathrm{AcOH}$, and $10 \mathrm{mM} \mathrm{CTAB}, \mathrm{pH}$ 8.2), although diminished due to their weak interaction with positively charged CTAB micelles. Slightly lower absolute values of mobilities in BGE VIII as compared with BGE VII are apparently caused by the higher concentration of CTAB in BGE VIII (10 mM) versus BGE VII (5 mM). Reverse migration behavior was observed for DAP derivatives containing the aromatic group (A6) in BGE VIII and the acidic DAP derivative $\mathbf{C} 4$ in BGE VII and BGE VIII. These two derivatives form strong complexes with cationic CTAB micelles, resulting in a positive charge and cationic migration with a low positive mobility (4.9 MU) for $\mathbf{A} 6$ and a high positive mobility (28.0-28.6 MU) for C4. It is worth noting that in some cases the diastereomers of the DAP derivatives were partially or completely resolved in achiral media-by CZE in BGE $\mathrm{V}$ and by MEKC in BGE VI and BGE VII (see Fig.3, Fig.4 in the next section). Thus, these separations allowed determination of effective electrophoretic mobilities for both diastereomers (enantiomer pairs) of these compounds (see Table 4).
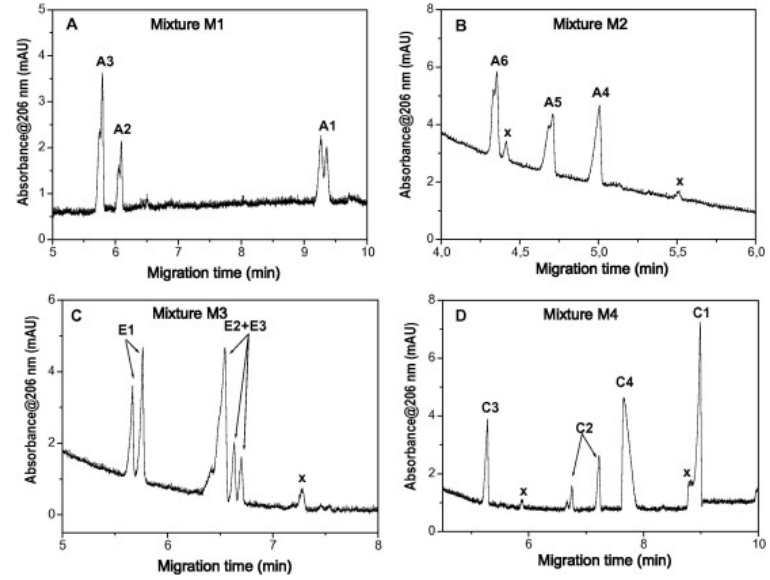

Fig.3. MEKC separation of partial mixtures of DAP derivatives in BGE VI: (A) mixture M1 (A1-A3); (B) mixture M2 (A4-A6); (C) mixture M3 (E1-E3); (D) mixture M4 (C1-C4). Sample injection: 10 mbar $\times 5 \mathrm{~s}, \mathrm{x}$, nonidentified

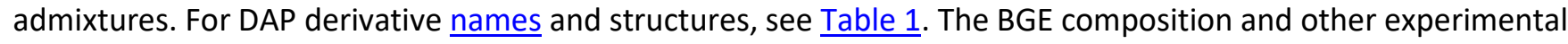
conditions are given in Table 2 and in "Materials and Methods".

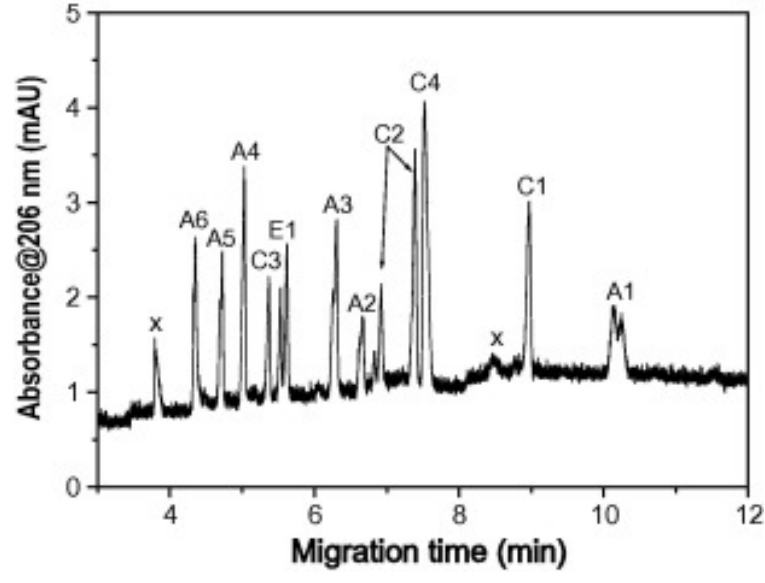


Fig.4. MEKC separation of the 11 DAP derivatives in BGE VI. Sample injection: 10 mbar $\times 5 \mathrm{~s}, \mathrm{x}$, nonidentified admixtures. For DAP derivative names and structures, see Table 1. The BGE composition and other experimental conditions are given in Table 2 and in "Materials and Methods".

\section{Separation of DAP derivatives}

From the eight BGEs tested, the largest differences in electrophoretic mobilities for DAP derivatives were found in BGE VI (0.5 M AcOH [pH 2.54] and $60 \mathrm{mM} \mathrm{SDS).} \mathrm{Consequently,} \mathrm{the} \mathrm{separation} \mathrm{of} \mathrm{mixtures} \mathrm{of} \mathrm{DAP} \mathrm{derivatives}$ was carried out by MEKC in this BGE. First, four partial mixtures of the analytes were constituted according to similarity of their $N$-acyl substituent (Table 1). The mixture M1 was constituted from compounds $\mathbf{A} 1$ to $\mathbf{A} \mathbf{3}$ with linear and branched $\mathrm{C} 2$ and $\mathrm{C} 4$ aliphatic acyl groups; mixture $\mathrm{M} 2$ from compounds $\mathbf{A} 4$ and $\mathbf{A} 5$ with linear and branched $\mathrm{C} 5$ aliphatic acyl groups, respectively, and compound $\mathbf{A 6}$ with an aromatic acyl group; mixture M3 from compounds E1 to E3containing esterified carboxyl groups; and mixture M4 composed of compounds $\mathbf{C} \mathbf{1}$ to $\mathbf{C 4}$, which contain free carboxylic groups. Fig. 3 shows complete MEKC separations for all components of mixtures $\mathrm{M} 1, \mathrm{M} 2$, and $\mathrm{M} 4$, including a complete or partial separation of the diastereomers of $\mathbf{A 1}, \mathbf{A 2}, \mathbf{A 3}, \mathbf{A 5}, \mathbf{A} \mathbf{6}, \mathbf{C 1}$, and $\mathbf{C 2}$, whereas in mixture $\mathrm{M} 3$ a baseline separation of the diastereomers of $\mathbf{E} 1$ was achieved but E2 and E3 and their diastereomers comigrated. The addition of organic modifiers (methanol or acetonitrile) to the BGE did not improve the separation of these two compounds and their diastereomers. Finally, using this optimized BGE, a mixture of all DAP derivatives, with the exception of comigrating derivatives E2 and E3, was separated by MEKC within a short time of $11 \mathrm{~min}$ (Fig. 4).

\section{Enzyme inhibition}

All DAP derivatives were examined for their ability to inhibit the catalytic activity of HiDapE enzyme. Of the 13 compounds tested, only $\mathbf{A} 1$ showed a weak inhibition of the catalytic activity with an $\mathrm{IC}_{50}$ value of $17 \mathrm{mM}$. These data suggest that the amino moiety of mono- $N$-succinyl-DAP forms an important interaction within the active site of DapE given that the acylated amino acids did not inhibit enzymatic activity. Alternatively, the acylated versions of these amino acids may introduce a repulsive steric interaction because of bulky alkyl groups, thereby preventing enzyme binding. All of the DAP derivatives were also examined for their ability to inhibit EcArgE. Some of the DAP derivatives exhibited a weak inhibition toward EcArgE; the best inhibitor was E1, with an $\mathrm{IC}_{50}$ value of $480 \mu \mathrm{M}$, thereby providing a promising lead structure for further studies on ArgE inhibitors. The other DapE inhibitors that showed a dose-dependent response to $E c A r g E$ were $\mathbf{A 1}, \mathbf{C 1}$, and $\mathbf{C} \mathbf{3}$, with $\mathrm{IC}_{50}$ values of $2.63,2.11$, and $1.28 \mathrm{mM}$, respectively, whereas the remaining DAP derivatives did not inhibit EcArgE. It implies that both DapE and ArgE active sites possess strict substrate specificity with regard to both functional groups and stereochemistry.

\section{Conclusions}

The data presented here proved that IR and NMR spectroscopies and capillary electromigration methods, CZE and MEKC, represent powerful tools for structural analysis, purity determination, separation, and physicochemical characterization of amino acids and their derivatives. Structural features of mono- $N$-acyl derivatives of 2,6-DAP were characterized by IR and NMR spectroscopies, whereas purity degree and effective electrophoretic mobilities of cationic and anionic forms of these compounds in acidic and alkaline classical or isoelectric BGEs with and without anionic (SDS) or cationic (CTAB) detergents were determined by CZE and MEKC methods. The best separation of DAP derivatives, including diastereomers of some of them, was achieved by MEKC in an acidic BGE (500 mM acetic acid, pH 2.54) with micellar pseudophase constituted by anionic detergent, $60 \mathrm{mM}$ SDS. None of the analyzed DAP derivatives worked as an effective inhibitor of catalytic activity of the DapE from $\underline{H}$. influenza, but one derivative- $N$-fumaryl, Me-ester-DAP-was found to be a moderate inhibitor of ArgE from E. coli, thereby providing a promising lead structure for further studies on ArgE inhibitors. 


\section{Acknowledgments}

This work was supported by the Czech Science Foundation (P206/12/0453 and 13-17224S), the Grant Agency of the Academy of Sciences of the Czech Republic (IAA400550614), the Academy of Sciences of the Czech Republic (RVO 61388963), and the National Institutes of Health (R15 Al085559-01A1 to R.C.H.). S. Vašíčková is thanked for measurement of IR spectra.

\section{References}

[1]W.J. Hierholzer, J.S. Garner, A.B. Adams, D.E. Craven, D.W. Fleming, S.W. Forlenza, M.J.Gilchrist, D.A. Goldma nn, E.L. Larson, C.G. Mayhall, R.D. McCormick, R.L. Nichols, C.E. Edmiston, D.G. Maki, G. Pugliese, R.A. W einstein, O.C. Tablan, F.C. Tenover, W.J.Martone, R.F. Gaynes, W.R. Jarvis, M.F. Favero Recommendations for preventing the spread of vancomycin resistance: recommendations of the Hospital Infection Control Practices Advisory Committee (HICPAC) Am. J. Infect. Control, 23 (1995), pp. 87-94

[2] R.E.W. Hancock Peptide antibiotics Lancet, 349 (1997), pp. 418-422

[3] R.A. Howe, K.E. Bowker, T.R. Walsh, T.G. Feest, A.P. MacGowanVancomycin-resistant Staphylococcus aureus Lancet, 351 (1998), p. 602

[4] S.B. Levy The challenge of antibiotic resistance Sci. Am., 278 (1998), pp. 46-53

[5] M. Teuber Spread of antibiotic resistance with food-borne pathogens Cell. Mol. Life Sci., 56 (1999), pp. 755763

[6] P.J. Dolin, M.C. Raviglione, A. Kochi Global tuberculosis incidence and mortality during 1990-2000 Bull. WHO, 72 (1994), pp. 213-220

[7] M.C. Raviglione, D.E. Snider, A. Kochi Global epidemiology of tuberculosis: morbidity and mortality of a worldwide epidemic JAMA, 273 (1995), pp. 220-226

[8]J.R. Miller, S. Dunham, I. Mochalkin, C. Banotai, M. Bowman, S. Buist, B. Dunkle, D. Hanna, H.J. Harwood, M.D. Huband, A. Karnovsky, M. Kuhn, C. Limberakis, J.Y. Liu, S.Mehrens, W.T. Mueller, L. Narasimhan, A. Ogde n, J. Ohren, J.V.N.V. Prasad, J.A. Shelly, L. Skerlos, M. Sulavik, V.H. Thomas, S. VanderRoest, L.A. Wang, Z. G. Wang, A. Whitton, T. Zhu, C.K. Stover A class of selective antibacterials derived from a protein kinase inhibitor pharmacophore Proc. Natl. Acad. Sci. U.S.A., 106 (2009), pp. 1737-1742

[9]L. Monincová, M. Buděšínský, J. Slaninová, O. Hovorka, J. Cvačka, Z. Voburka, V. Fučík, L. Borovičková, L. Bedn arová, J. Straka, V. Čerovský Novel antimicrobial peptides from the venom of the eusocial bee Halictus sexcinctus(Hymenoptera: Halictidae) and their analogs Amino Acids, 39 (2010), pp. 763-775

[10]L. Monincová, J. Slaninová, V. Fučík, O. Hovorka, Z. Voburka, L. Bednarová, P. Maloň, J.Štokrová, V. Čerovský Lasiocepsin, a novel cyclic antimicrobial peptide from the venom of eusocial bee Lasioglossum laticeps (Hymenoptera: Halictidae) Amino Acids, 43 (2012), pp. 751-761

[11]P. Niederhafner, L. Bednarová, M. Buděšínský, M. Šafařík, S. Ehala, J. Ježek, L.Borovičková, V. Fučík, V. Čerovs ký, J. Slaninová Melectin MAPs: the influence of dendrimerization on antimicrobial and hemolytic activity Amino Acids, 39 (201 0), pp. 1553-1561

[12]J.Y. Kim, S.C. Park, M.Y. Yoon, K.S. Hahm, Y. Park C-terminal amidation of PMAP-23: translocation to the inner membrane of gram-negative bacteria Amino Acids, 40 (2011), pp. 183-195

[13]J. Hlaváček, J. Pícha, V. Vaněk, J. Jiráček, J. Slaninová, V. Fučík, M. Buděšínský, D.Gilner, R.C. Holz Inhibitors of $\boldsymbol{N}^{\alpha}$-acetyl-I-ornithine deacetylase: synthesis, characterization, and analysis of their inhibitory potency Amino Acids, 38 (2010), pp. 1155-1164

[14]G. Scapin, J.S. Blanchard Enzymology of bacterial lysine biosynthesis Adv. Enzymol., 72 (1998), pp. 279-324

[15]T.L. Born, J.S. Blanchard Structure/function studies on enzymes in the diaminopimelate pathway of bacterial cell wall biosynthesis Curr. Opin. Chem. Biol., 3 (1999), pp. 607-613

[16]J.M. Girodeau, C. Agouridas, M. Masson, R. Pineau, F. Legoffic The lysine pathway as a target for a new genera of synthetic antibacterial antibiotics J. Med. Chem., 29 (1986), pp. 1023-1030

[17]D.M. Gillner, D.P. Becker, R.C. Holz Lysine biosynthesis in bacteria: a metallodesuccinylase as a potential antimicrobial target J. Biol. Inorg. Chem., 18 (2013), pp. 155-163 
[18]D.L. Bienvenue, D.M. Gilner, R.S. Davis, B. Bennett, R.C. Holz Substrate specificity, metal binding properties, and spectroscopic characterization of the DapE-encoded N-succinyl-I,I-diaminopimelic acid desuccinylase from Haemophilus influenzae Biochemistry, 42 (2003), pp. 10756-10763

[19]M. Karita, M.L. Etterbeek, M.H. Forsyth, M.K.R. Tummuru, M.J. Blaser Characterization of Helicobacter pylori dapE and construction of a conditionally lethal dapE mutant Infect. Immun., 65 (1997), pp. 41584164

[20]M.S. Pavelka, W.R. Jacobs Biosynthesis of diaminopimelate, the precursor of lysine and a component of peptidoglycan, is an essential function of Mycobacterium smegmatis J. Bacteriol., 178 (1996), pp. 64966507

[21]C.A. Hutton, M.A. Perugini, J.A. Gerrard Inhibition of lysine biosynthesis: an evolving antibiotic strategy Mol. BioSyst., 3 (2007), pp. 458-465

[22]V. Vaněk, J. Pícha, M. Buděšínský, M. Šanda, J. Jiráček, R.C. Holz, J. Hlaváček Synthesis of N-succinyl-I, Idiaminopimelic acid mimetics via selective protection Protein Pept. Lett., 17 (2010), pp. 405-409

[23]M. Geiger, A.L. Hogerton, M.T. Bowser Capillary electrophoresis Anal. Chem., 84 (2012), pp. 577-596

[24]M. Silva Micellar electrokinetic chromatography: a practical overview of current methodological and instrumental advances Electrophoresis, 32 (2011), pp. 149-165

[25]M. Silva Micellar electrokinetic chromatography: a review of methodological and instrumental innovations focusing on practical aspects Electrophoresis, 34 (2013), pp. 141-158

[26]V. Poinsot, M.A. Carpene, J. Bouajila, P. Gavard, B. Feurer, F. Couderc Recent advances in amino acid analysis by capillary electrophoresis Electrophoresis, 33 (2012), pp. 14-35

[27]V. Poinsot, V. Ong-Meang, P. Gavard, F. Couderc Recent advances in amino acid analysis by capillary electromigration methods, 2011-2013 Electrophoresis, 35 (2014), pp. 50-68

[28]C. Desiderio, F. lavarone, D.V. Rossetti, I. Messana, M. Castagnola Capillary electrophoresis-mass spectrometry for the analysis of amino acids J. Sep. Sci., 33 (2010), pp. 2385-2393

[29]V. Kašička, Z. Prusík, P. Sázelová, M. Chiari, I. Mikšík, Z. Deyl External electric field control of electroosmotic flow in non-coated and coated fused-silica capillaries and its application for capillary electrophoretic separations of peptides J. Chromatogr. B, 741 (2000), pp. 43-54

[30]W.C. McGregor, S.I. Swierczek, B. Bennett, R.C. Holz ArgE-encoded N-acetyl-I-ornithine deacetylase from Escherichia coli contains a dinuclear metalloactive site J. Am. Chem. Soc., 127 (2005), pp. 1410014107

[31] G.M. Janini, H.J. Issaq Selection of buffers in capillary zone electrophoresis: application to peptide and protein analysis Chromatographia, 53 (2001), pp. S18-S26

[32]V. Kašička Capillary electrophoresis of peptides Electrophoresis, 20 (1999), pp. 3084-3105

[33]G.K.E. Scriba, A. Psurek Separation of peptides by capillary electrophoresis P. SchmittKopplin (Ed.), Capillary Electrophoresis, Humana, Totowa, NJ (2008), pp. 483-506

[34]V. Kašička Recent developments in CE and CEC of peptides [2009-2011] Electrophoresis, 33 (2012), pp. 4873

[35]P.G. Righetti, R. Sebastiano, A. Citterio Capillary electrophoresis and isoelectric focusing in peptide and protein analysis Proteomics, 13 (2013), pp. 325-340

[36]V. Šolínová, V. Kašička, D. Koval, T. Barth, A. Ciencialová, L. Žáková Analysis of synthetic derivatives of peptide hormones by capillary zone electrophoresis and micellar electrokinetic chromatography with ultraviolet-absorption and laser-induced fluorescence detection J. Chromatogr. B, 808 (2004), pp. 7582

[37]D. Koval, V. Kašička, J. Jiráček, M. Collinsova, T.A. Garrow Determination of dissociation constant of phosphinate group in phosphinic pseudopeptides by capillary zone electrophoresis J. Chromatogr. B, 770 (2002), pp. 145-154

${ }^{1}$ These authors contributed equally to this article. 
2 Abbreviations used: ArgE, $N^{\alpha}$-acetyl-I-ornithine deacetylase; mDAP, meso-diaminopimelate or mesodiaminopimelic acid; DapE, dapE-encoded $N$-succinyl-I,I-diaminopimelic acid desuccinylase; DAP, 2,6diaminopimelic acid; HPLC, high-performance liquid chromatography; IR, infrared; NMR, nuclear magnetic resonance; CZE, capillary zone electrophoresis; MEKC, micellar electrokinetic chromatography; BGE, background electrolyte; SDS, sodium dodecyl sulfate; CTAB, cetyltrimethylammonium bromide; Tris, tris(hydroxymethyl)aminomethane; $\mathrm{H}_{3} \mathrm{PO}_{4}$, phosphoric acid; $\mathrm{AcOH}$, acetic acid; $\mathrm{NaOH}$, sodium hydroxide; IDA, iminodiacetic acid; ACN, acetonitrile; $\mathrm{MeOH}$, methanol; FT, Fourier transform; UV, ultraviolet; HiDapE, DapE from Haemophilus influenzae; UV-Vis, ultraviolet-visible; EcArgE, ArgE from Escherichia coli; L-NAO, $N^{\alpha}$-acetyl-I-ornithine; MU, mobility units.

\section{Appendix A. Supplementary data}

Download Word document (5MB)Help with doc files

Supplementary data 1. 